\title{
Correction to: Predicting the effectiveness of protected areas of Natura 2000 under climate change
}

Mst Umme Salma Nila ${ }^{1}$, Carl Beierkuhnlein ${ }^{1,2}$, Anja Jaeschke ${ }^{2}$, Samuel Hoffmann ${ }^{2}$ and Md Lokman Hossain ${ }^{1,3,4^{*}}$

\section{Correction to: Ecol Process \\ https://doi.org/10.1186/s13717-019-0168-6}

In the original publication of this article (Nila and Hossain 2019), co-authors 'Carl Beierkuhnlein, Anja Jaeschke and Samuel Hoffmann' need to be added to the author list.

Additionally, two parts of the Declarations section below need to be updated:

\section{Acknowledgements}

This work was supported by the European H2020 Project ECOPOTENTIAL, grant agreement No. 641762.

\section{Authors' contributions}

This article is a part of MSC thesis of MUSN for the partial fulfillment of MSC in Global Change Ecology, University of Bayreuth. CB, AJ and SH supervised this work and contributed the study design, statistical analysis and thesis preparation. MLH prepared the manuscript with the help of MUSN. All authors read and approved the final manuscript.

The author list in the original publication has been corrected.

\section{Author details}

${ }^{1}$ Global Change Ecology, International Elite Study Programme, University of Bayreuth, Universitätsstraße 30, 95447 Bayreuth, Germany. ${ }^{2}$ Department of Biogeography, University of Bayreuth, Universitätsstraße 30, 95447 Bayreuth, Germany. ${ }^{3}$ Department of Geography, Hong Kong Baptist University, 15 Baptist University Road, Kowloon Tong, Hong Kong. ${ }^{4}$ Department of Environmental Protection Technology, German University Bangladesh, Gazipur 1702, Bangladesh.

Received: 14 June 2019 Accepted: 17 June 2019

Published online: 12 July 2019

\section{Reference}

Nila MUS, Hossain ML (2019) Predicting the effectiveness of protected areas of

Natura 2000 under climate change. Ecol Process 8:13 https://doi.org/10.1186/

s13717-019-0168-6

* Correspondence: lokmanbbd@gmail.com

The original article can be found online at https://doi.org/10.1186/s13717-01 9-0168-6

${ }^{1}$ Global Change Ecology, International Elite Study Programme, University of Bayreuth, Universitätsstraße 30, 95447 Bayreuth, Germany

${ }^{3}$ Department of Geography, Hong Kong Baptist University, 15 Baptist

University Road, Kowloon Tong, Hong Kong

Full list of author information is available at the end of the article 